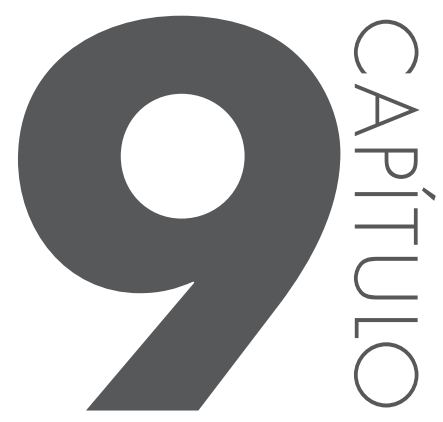

\title{
HISTOLOGIA dA CAVIDADE ORAL
}

Ricardo Bentes Azevedo

Jorge Faber

Soraya Leal

Carolina Lucci

A cavidade bucal é a porta natural de entrada de alimentos para o organismo e a abertura do sistema digestivo. É constituída por uma cavidade virtual, o Vestíbulo (a região que circunscreve a gengiva e as arcadas dentárias), e uma cavidade real, a Cavidade Oral propriamente dita (a região posterior à gengiva e às arcadas dentárias). Está associada a funções básicas e essenciais para o bem-estar da pessoa como mastigação, fonação e deglutição. 
Por uma questão meramente didática, todas as vezes que citarmos Cavidade Bucal estaremos nos referindo à boca como um todo (vestíbulo mais cavidade oral propriamente dita). Quando citarmos Cavidade Oral, estaremos nos referindo a cavidade bucal propriamente dita.

A cavidade bucal é limitada anteriormente pelos lábios; posteriormente pelo istmo das fauces; lateralmente pelas bochechas; inferiormente pelo assoalho bucal e superiormente pelo palato duro e pelo palato mole.

\subsection{MUCOSA BUCAL}

Formada por duas camadas de tecido de origens embriológicas distintas: o epitélio e a lâmina própria. O epitélio pode ser do tipo não-queratinizado, para-queratinizado ou queratinizado (Quadro 9.1), e é classificado como estratificado pavimentoso. O tecido conjuntivo que forma a lâmina própria é composto por fibras colágenas, fibroblastos, células de defesa, vasos sanguíneos e nervos. Os dois tecidos interagem por meio das papilas conjuntivas da lâmina própria e as cristas epiteliais que se formam no epitélio sobrejacente. 


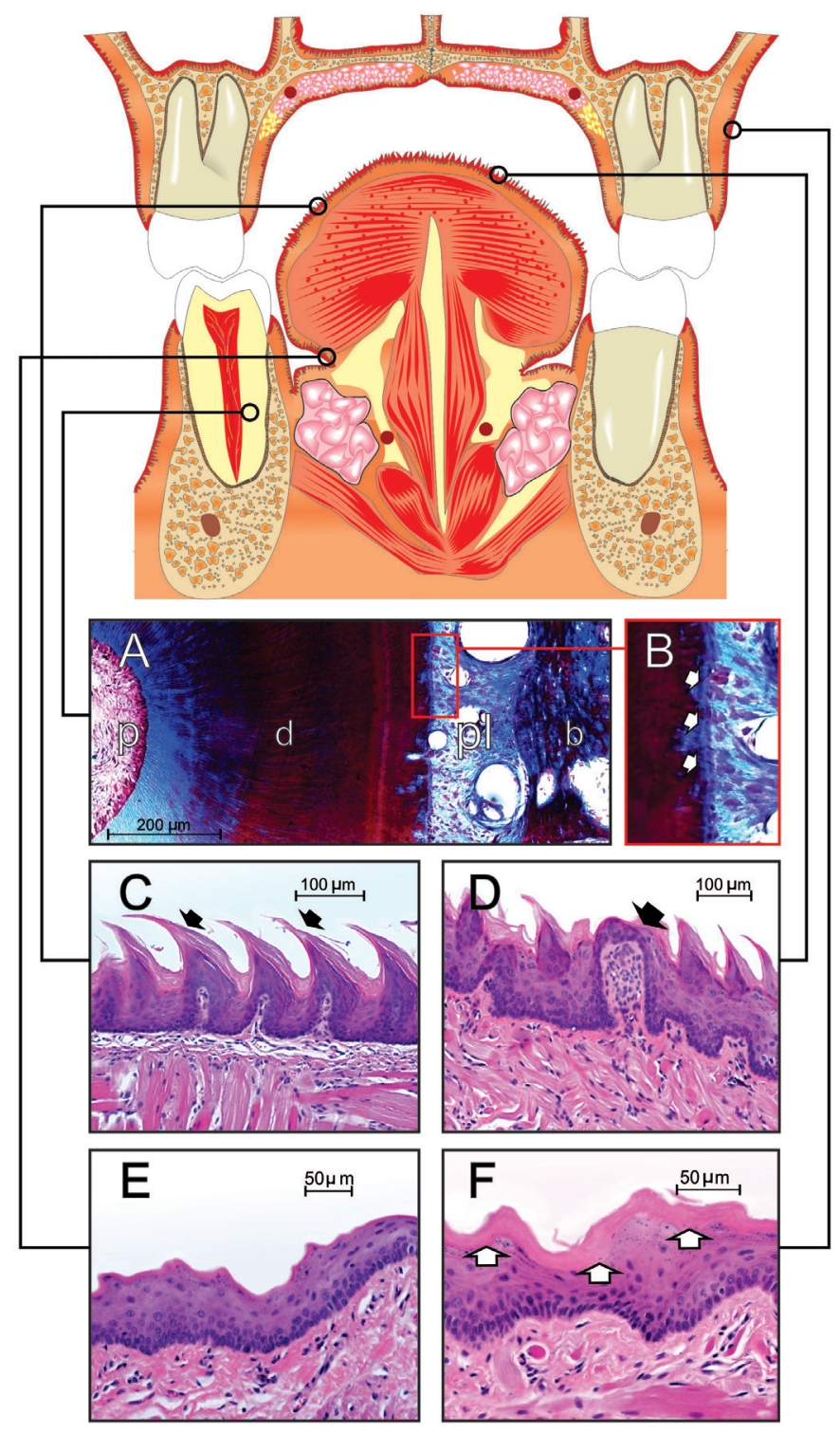

Figura 9.1 - 0 esquema representa um corte coronal na face, na altura dos pré-molares. Em " $A$ " a fotomicrografia mostra os tecidos pulpar ( $\mathrm{p}$ ), dentinário (d), ligamento periodontal (PL) e ósseo (b). " $\mathrm{B}$ " é um detalhe de " $\mathrm{A}$ ", salientando por meio de setas o cemento, que é o delgado tecido duro que recobre a raiz dentária e provê inserção para o ligamento periodontal. Em " $C$ " as setas indicam as papilas filiformes - as mais numerosas da língua- em formato de ondas. " $D$ " realça com a seta uma papila fungiforme ladeada por papilas filiformes. " $E$ " e " $F$ " mostram a mucosa em variadas regiões da boca. A camada de queratina pode ser visualizada em " $F$ " (setas). 
A mucosa da cavidade bucal é dividida em:

mastigatória,

de revestimento e

especializada.

A divisão da mucosa em três grandes grupos está relacionada ao tipo de epitélio que reveste o tecido conjuntivo subjacente. Nas regiões nas quais são maiores os impactos sofridos pela mastigação são maiores, a mucosa deve ser mais firme e resistente e, portanto, recoberta por um epitélio que pode variar entre o paraqueratinizado e o queratinizado. Nas áreas nas quais a demanda mastigatória não é tão grande, o epitélio de revestimento é normalmente bastante fino e composto por células não queratinizadas. A região lingual distingue-se das demais áreas da cavidade bucal por apresentar uma grande quantidade de botões gustativos. Por esta razão, a região do dorso da língua é classificada como mucosa especializada.

- Mucosa mastigatória: estende-se sobre a região do palato duro e gengiva que circunda os dentes inferiores e superiores. O epitélio que reveste o palato duro é do tipo queratinizado e está sobreposto a uma lâmina própria rica em tecido conjuntivo fibroso. Com exceção da região da rafe palatina, na qual a lâmina própria está diretamente inserida sobre o periósteo, existe uma extensa camada de submucosa entre o osso e a lâmina própria. A composição desta submucosa varia de acordo com a região: na porção anterolateral há o predomínio de tecido adiposo, enquanto na região posterolateral há uma grande concentração de glândulas salivares menores. Já a porção da mucosa mastigatória representada pela gengiva apresenta os três tipos de epitélio: não-queratinizado, localizado na região do sulco gengival e col interdental; paraqueratinizado e queratinizado revestindo a gengiva marginal e inserida.

- Mucosa de revestimento: composta pela mucosa que reveste internamente os lábios e a bochecha, o ventre da língua, o assoalho da cavidade bucal, o palato mole e parte da porção lingual do processo alveolar mandibular. Tem como característica apresentar uma fina camada de tecido epitelial recobrindo uma lâmina própria bastante vascularizada e menos fibrosa quando comparada à lâmina própria da mucosa mastigatória. Recobre essencialmente tecido muscular e, em função dessa característica, apresenta certa flexibilidade. Na região do palato mole, a submucosa é rica em glândulas salivares menores além de botões gustativos.

- Mucosa especializada: localizada sobre o dorso da língua. Protege a musculatura lingual e, nos 2/3 anteriores da língua, as papilas filiformes e fungiformes, que são recobertas por epitélio queratinizado e não queratinizado, 
respectivamente. Na porção lateral e no $1 / 3$ posterior da língua reveste as papilas folheadas e valadas. As papilas valadas, em torno de 8 a 12, situam-se no "v" lingual e têm papel importante para a percepção do sabor. Ao longo das paredes de cada uma destas papilas, que podem variar em número, encontra-se uma grande quantidade de botões gustativos.

\subsection{LÁBIOS}

Localizados anteriormente ao vestíbulo, são duas pregas musculares (músculo orbicular da boca), formadas de músculo estriado esquelético, e revestidas em suas três faces. Externamente, é revestido por pele. Nesta região, o epitélio de revestimento é pavimentoso estratificado queratinizado. No tecido conjuntivo abaixo, encontramos pelos, glândulas sudoríparas e glândulas sebáceas. A porção intermediária, conhecida como zona vermelha do lábio, apresenta um epitélio estratificado pavimentoso levemente queratinizado, e cujo tecido conjuntivo adjacente é ricamente capilarizado. Finalmente, a face interna é recoberta pela mucosa bucal. Nesse caso, o epitélio é estratificado pavimentoso não queratinizado, com lâmina própria de tecido conjuntivo frouxo. No tecido conjuntivo, encontramos inúmeras glândulas mucosas, as glândulas labiais.

\subsection{BOCHECHAS}

Em vez de três faces, apresentam apenas duas: mas, da mesma forma que os lábios, apresentam um músculo central, o músculo bucinador, formado de fibras musculares estriadas esqueléticas. Externamente são resvestidas por pele e internamente por uma mucosa de epitélio estratificado pavimentoso não queratinizado e tecido conjuntivo frouxo rico em fibras elásticas que se prendem ao músculo da bochecha, evitando o pregueamento da mucosa durante o processo mastigatório, especialmente quando a boca está fechada. 


\subsection{PALATOS}

\subsubsection{PALATO DURO}

A mucosa do palato duro é formada por epitélio estratificado pavimentosoqueratinizado e tecido conjuntivo denso não modelado rico em glândulas mucosas, que continua com o periósteo do tecido ósseo (processos palatinos das maxilas e lâminas horizontais dos ossos palatinos) onde a mucosa está apoiada. Esta constituição permite que o alimento seja pressionado contra o palato duro durante a deglutição.

\subsubsection{PALATO MOLE}

Contínua ao palato duro, mas, em vez de osso, sua mucosa está apoiada em camadas de tecido muscular estriado esquelético e tecido conjuntivo fibroso, que impedem a passagem do ar no momento da deglutição. É formada por mucosa do tipo revestimento.

\subsection{LÍNGUA}

Situada na cavidade bucal propriamente dita (e parte na orofaringe), é um órgão muscular, formado de fibras estriadas esqueléticas, que tem importante função na condução do alimento para os dentes durante a mastigação, bem como para a faringe durante a deglutição. Além disso, a língua desempenha importantes tarefas-gustação, fonação e deglutição. Entre os feixes dos músculos intrínsecos da língua (aqueles têm origem e inserção no órgão), encontramos tecido conjuntivo com vasos sanguíneos e linfáticos, gânglios nervosos, nervos, tecido adiposo e tecido linfóide. Os músculos intrínsecos estão dispostos em três planos (longitudinal, transversal e vertical) que se cruzam em ângulo reto. Além destes músculos, existem também músculos estriados esqueléticos que se estendem da língua para a mandíbula, processo estiloide do crânio e palato mole, chamados de músculos extrínsecos, e que são responsáveis por mudar a posição do órgão.

Toda essa massa tecidual é recoberta por uma mucosa, cujas características variam de acordo com a região considerada. A porção da língua voltada para o palato é denominada dorso lingual e a porção voltada para o assoalho bucal é denominada ventre lingual. 


\subsubsection{DORSO LINGUAL}

É ordinariamente dividido em duas porções - corpo e base da língua - separadas pelo " $\mathrm{v}$ " lingual, localizado na sua parte mais posterior.

O corpo da língua constitui os dois terços anteriores do dorso da língua e apresenta uma grande quantidade de pequenas projeções da mucosa chamadas papilas linguais. Dependendo de suas características morfológicas, são chamadas de: papilas filiformes, papilas fungiformes ou papilas circunvaladas.

Papilas filiformes. Alongadas e cônicas, apresentam um eixo de tecido conjuntivo denso recoberto por epitélio estratificado pavimentoso queratinizado, têm de 2 a $3 \mathrm{~mm}$ de comprimento e recobrem praticamente todo o dorso do corpo da língua. Não apresenta botões corpúsculos gustativos (descritos abaixo).

Papilas fungiformes. Distribuídas isoladamente entre as papilas filiformes, são mais numerosas nos lados, bem como próximo ao ápice da língua. Como o próprio nome se refere, têm forma de cogumelo e apresentam uma região central de tecido conjuntivo denso, rico em capilares sanguíneos, e são recobertas por epitélio estratificado não queratinizado. Apresentam poucas papilas gustativas.

Papilas circunvaladas. Com cerca de $2 \mathrm{~mm}$ de diâmetro, são as maiores papilas. Elas estão afundadas na mucosa, mas sobressaindo-se ligeiramente sobre a superfície da língua. Essas papilas são circundadas por uma fenda, característica que lhes dá o nome. O interior de tecido conjuntivo é revestido por epitélio pavimentoso estratificado não queratinizado. Nas superfícies laterais, encontramos numerosos corpúsculos gustativos. Glândulas serosas (de Von Ebner), cujas porções secretoras estão localizadas entre o tecido muscular subjacente, desembocam no fundo das fendas. A secreção dessas glândulas "limpam" continuamente a superfície dos botões gustativos, deixando-os sempre prontos para um novo estímulo. As papilas circunvaladas desenham o "V" lingual, e são em número que varia de oito a 12 .

Botões ou corpúsculos gustativos. Apresentam-se pouco corados no interior do epitélio. São ovais, em forma de barril, e com o eixo maior em torno de $72 \mu \mathrm{m}$, indo da lâmina basal até próximo a superfície. O epitélio sobre cada corpúsculo gustativo apresenta uma pequena abertura, o poro gustativo ou fosseta gustativa.

Três tipos celulares são encontrados nos corpúsculos gustativos:

1. células basais, encontradas principalmente próximas à lâmina basal, são consideradas células-tronco e dão origem aos outros dois tipos celulares, cuja renovação acontece em aproximadamente dias;

2. células neuroepiteliais, célula alongada, que se estende desde a lâmina basal até o poro gustativo. Seu citoplasma se cora mal e apresenta em sua superfície apical microvilosidades que se projetam no poro gustativo. Terminações 
nervosas são encontradas próximas a essas células; e

3. células de sustentação, localizadas entre as células neuroepiteliais, também se estendem desde a lâmina basal até próximo à superfície e apresentam microvilosidades que se projetam no poro gustativo. Coram-se mais fortemente do que as células neuroepiteliais.

Os botões gustativos recebem o estímulo sensorial responsável pela percepção do paladar. Existem quatro sensações gustativas fundamentais: doce, amargo, ácido (azedo) e salgado. Mais recentemente, o quinto sabor - umami, o sabor do aminoácido glutamato - foi identificado. A maioria dos botões gustativos responde a todos estes estímulos em graus variados; no entanto, cada papila tem maior grau de sensibilidade para uma ou duas das sensações gustativas. O cérebro detecta o tipo de gosto pela razão de estimulação entre as variadas papilas gustativas. Isto é, se uma papila que detecta principalmente ácido é estimulada com maior intensidade do que as papilas que respondem mais a outros gostos, o cérebro interpreta a sensação como de azedo, embora outras papilas tenham sido estimuladas, em menor extensão, ao mesmo tempo. As papilas gustativas são também encontradas no palato mole, epiglote e faringe.

A base da língua constitui o terço posterior do dorso da língua. Apresenta uma superfície irregular em virtude das tonsilas linguais. Tonsilas são aglomerados de tecidos linfoides, localizados abaixo e em contato com o epitélio da porção inicial da orofaringe. No caso das tonsilas linguais, seu revestimento é de epitélio estratificado não queratinizado que se invagina em direção à lâmina própria, formando uma cripta. Abaixo do epitélio, encontramos tecido linfoide nodular, circundado lateralmente por tecido conjuntivo denso.

Ventre lingual. É a face inferior da língua. É lisa e revestida por epitélio pavimentoso estratificado não queratinizado.

\subsection{DENTES}

Os dentes desempenham papel importante na mastigação, na fala, na expressão das emoções e também na estética facial, uma vez que o sorriso representa papel relevante na beleza da face.

A raça humana apresenta duas dentições - a decídua, constituída por 20 dentes e a permanente, composta por 32 dentes. Tanto dentes decíduos quanto permanentes se dividem em dois grupos funcionais: anteriores e posteriores. A bateria anterior é composta pelos incisivos centrais, incisivos laterais e caninos, teme tem por função apreender e cortar o alimento. $\mathrm{Na}$ sequência, este alimento é direcionado para a região posterior, que acomoda os molares (dentição decídua) e pré-molares e 
molares (dentição permanente), cuja principal função é triturar e moer o alimento. Assim, a perda de um elemento dental pode acarretar em diminuição da função mastigatória que será mais grave quanto maior for o número de dentes perdidos. Ademais, alterações na fala e na estética decorrentes da falta de um ou mais dentes influenciam negativamente a qualidade de vida da pessoa.

Ambas as dentições se originam da lâmina dentária, que se desenvolve durante a vida intra-uterina. Os dentes, independentemente de serem decíduos ou permanentes, são formados por tecidos, como pode ser visualizado na figura XX.

A região do dente que, em condições saudáveis, se projeta acima da gengiva é chamada de coroa (apenas uma pequena porção da coroa fica abaixo desta linha). A parte do dente que está situada em pequenas cavidades da maxila ou da mandíbula, os alvéolos, é chamada de raiz. Na região central de cada dente, existe a cavidade pulpar, preenchida pela polpa dentária.

As partes duras do dente são formadas por esmalte, dentina, e cemento.

Podemos dizer que a dentina forma o corpo do dente e ela é o tecido que constitui quase a totalidade do marfim do elefante. Circunda toda a câmara pulpar e é mais espessa na região da coroa. Nesta região, a dentina é revestida pelo esmalte. Já na região da raiz, é revestida pelo cemento.

As partes moles associadas ao dente são polpa, ligamento periodontal, e gengiva.

Ligamento periodontal e o osso dos alvéolos constituem o periodonto, responsável pela inserção do dente ao osso mandibular e maxilar. Alguns autores consideram o cemento como parte do periodonto.

\subsection{ESMALTE}

Em comparação aos outros tecidos duros do corpo humano (osso, cemento e dentina), é o que apresenta a maior concentração mineral. Constituído quase que exclusivamente de fosfato de cálcio sob a forma de cristais de hidroxiapatita (Ca10(PO4)6(OH)3, apresenta apenas $2 \%$ a $4 \%$ de matéria orgânica, água e proteínas. Ao contrário da dentina e do tecido ósseo, o esmalte não contém colágeno em sua composição. O esmalte é totalmente desprovido de vascularização e inervação.

A formação do esmalte dentário é um processo regulado por células chamadas ameloblastos e envolve duas fases: secreção e maturação. Na primeira fase os ameloblastos secretam proteínas da matriz do esmalte, tais como amelogenina, ameloblastina e enamelina. A fase de maturação inclui remoção do material orgânico e deposição de fosfato de cálcio.

A hidroxiapatita está arranjada sob a forma de bastonetes ou prismas. O curso destes prismas parece estar perfeitamente ajustado às necessidades dos dentes de fracionar e esmagar os alimentos. Eles se dispõem emergindo principal- 
mente de forma perpendicular à superfície da dentina e, em seguida, são alvo de uma inclinação pronunciada em direção à borda incisal ou oclusal. Circundando os prismas há uma região um pouco mais rica em matéria orgânica, a bainha do esmalte.

No momento da erupção dentária, o contato com a sua célula formadora ameloblasto - é perdido e ela degenera, o que impossibilita reparo ou regeneração do tecido.

\subsubsection{DENTINA}

O tecido duro dentinário é forrado, internamente, por uma camada de células chamadas odontoblastos. Elas são responsáveis pela secreção da matriz orgânica, formada por fibras colágenas do tipo 1, e pequena quantidade de substância fundamental amorfa. A matriz inorgânica é constituída principalmente de fosfato de cálcio (hidroxiapatita), numa concentração menor do que a do esmalte, mas ainda maior do que a dos tecidos ósseos.

$\mathrm{Na}$ dentina encontramos inúmeros canalículos, os túbulos da dentina, que se irradiam desde a cavidade pulpar até a periferia. Prolongamentos apicais dos odontoblastos estendem-se para dentro dos canalículos, formando as chamadas fibras de Tomes.

\subsubsection{CEMENTO}

É onde o ligamento periodontal se conecta ao dente. Possui células chamadas de cementócitos na região apical da raiz, localizadas em lacunas, semelhantes aos osteócitos, e responsáveis pela síntese de matriz orgânica. Também apresentam prolongamentos que ocupam canalículos. Da mesma forma que os ossos, sua matriz orgânica é formada por colágeno e substância fundamental amorfa, e tem um conteúdo mineral de aproximadamente $50 \%$ de hidroxiapatita. Além da função de ancoragem do dente ao osso alveolar adjacente por meio do ligamento periodontal, o cemento tem outras funções. Por ser menos suscetível a reabsorção que a dentina, serve como camada protetora ao processo patológico de reabsorção dentária. Além disso, a deposição contínua de cemento na região apical compensa o rápido desgaste da superfície oclusal.

\subsubsection{POLPA DENTAL}

Ocupando a cavidade pulpar, é constituída no jovem por tecido conjuntivo mucoso, e no adulto por tecido conjuntivo frouxo, rico em fibras colágenas 
orientadas em todas as direções. Os odontoblastos, citados anteriormente, localizam-se na polpa, adjacentes à dentina. O tipo celular predominante no tecido conjuntivo pulpar são os fibroblastos; mas também são encontradas células de defesa, como, macrófagos, linfócitos, plasmócitos e eosinófilos. Encontramos ainda células-tronco pulpares, capazes de se diferenciarem em variados tecidos, quando devidamente estimuladas. A polpa é rica em vasos sanguíneos, linfáticos e nervos, que entram e saem da cavidade pulpar por meio do forâmen apical, que é uma abertura do ápice da raiz do dente.

\subsubsection{LIGAMENTO PERIODONTAL OU MEMBRANA PERIODONTAL}

É um tecido conjuntivo fibroso, constituído, principalmente, de espessas fibras colágenas, que circunda a raiz do dente e liga o dente, por meio do cemento, ao tecido ósseo adjacente. A orientação das fibras varia em variados níveis nos alvéolos, permitindo, porém, certo grau de movimentação dos dentes dentro dos mesmos. A membrana periodontal serve também de periósteo para o osso alveolar. Entre as fibras, especialmente próximo ao cemento, encontramos vasos sanguíneos, linfáticos e nervos, imersos em tecido conjuntivo frouxo. Embora a função mais óbvia do ligamento periodontal seja a de unir o dente ao cemento, todo este arranjo tecidual permite que o ligamento periodontal não só evite a reabsorção do osso alveolar por absorver grande parte da pressão que seria exercida sobre o mesmo durante a mastigação, mas também participe da contínua remodelação óssea que se ajusta à ininterrupta demanda dos movimentos dos dentes (importante também durante a movimentação dentária ortodôntica). Adicionalmente, o ligamento periodontal participa da nutrição das estruturas adjacentes e tem funções de própriocepção.

\subsection{GENGIVA}

É a parte da mucosa oral que reveste o osso alveolar. É subdividida em gengiva livre e gengiva inserida, dependendo da região. É composta de tecido epitelial estratificado pavimentoso queratinizado com numerosas papilas de conjuntivo denso que se projetam à base do epitélio. A gengiva inserida está firmemente presa aos processos alveolares da maxila e mandíbula e ao colo dos dentes. A mucosa gengiva livre tem normalmente epitélio não queratinizado. Entre o epitélio da gengiva livre e o esmalte, há um pequeno sulco circundando a coroa, o sulco gengival. 


\section{Quadro 9.1}

Os tecidos não mineralizados - polpa e ligamento periodontal - se caracterizam por serem altamente vascularizados e inervados. Os odontoblastos, responsáveis pela deposição de dentina, se localizam na periferia da polpa dentária, fazendo com que haja uma interação entre polpa e dentina. Desta forma, embora a dentina não possua nervos e vasos em seu interior, é altamente sensível pela comunicação propiciada pelos túbulos dentinários que conectam o prolongamento do odontoblasto, contido na dentina, com o seu corpo que se encontra na periferia pulpar.

\subsection{FARINGE}

A faringe transporta o alimento da boca para o esôfago; mas também o ar das cavidades nasais para a laringe, portanto é dividida em orofaringe e nasofaringe. A região da orofaringe é revestida por epitélio pavimentoso estratificado, enquanto que a nasofaringe é revestida por epitélio pseudo-estratificado cilíndrico ciliado. Numerosas glândulas há na lâmina própria, principalmente na nasofaringe. A faringe tem uma parede músculo membranosa incompleta anteriormente, onde é substituída pelas aberturas nasais posteriores, istmo orofaríngeo e comunicação da laringe.

\section{REFERÊNCIAS BIBLIOGRÁFICAS}

BERKOVITZ, B. K. B; HOLLAND, G. R.; MOXHAN, B. J. Anatomia, Embriologia e Histologia Bucal. 3 ed. São Paulo: Artmed - Grupo A, 2004.

BLOOM, W.; FAWCETT, D. W. Tratado de Histologia. Rio de Janeiro: Interamericana, 1985.

JUNQUEIRA, L. C.; CARNEIRO, J. Histologia Básica. 11 ed. Rio de Janeiro: Guanabara Koogan, 2008.

ROSS, M. H.; LYNN, J. R.; GORDON, I. K. Histology: A Text and Atlas. 3 ed. Maryland, USA: Williamns \& Wilkins, 1995.

SNELL, R. S. Histologia Clínica. Rio de Janeiro: Interamericana, 1985. 